\title{
STABILITY - INDICATING LC METHOD FOR THE SIMULTANEOUS DETERMINATION OF TELMISARTAN AND HYDROCHLOROTHIAZIDE IN DOSAGE FORM
}

\author{
KIRAN R. PATIL ${ }^{1,2}$, DEVANAND B. SHINDE *I \\ ${ }^{1}$ Department of Chemical Technology, Dr. Babasaheb Ambedkar Marathwada University, Aurangabad- 431004 (MS), India; \\ ${ }^{2}$ Wockhardt Research Centre, Aurangabad-431210 (MS), India
}

(Received: June 26, 2011 - Accepted: September 5, 2011)

\begin{abstract}
A simple, rapid, and precise method is developed for the quantitative simultaneous estimation of telmisartan and hydrochlorothiazide in combined pharmaceutical dosage form. A chromatographic separation of the two drugs was achieved with an ACE $5 \mathrm{C}_{18}(250 \times 4.6 \mathrm{~mm})$ analytical column using buffer-acetonitrile (55:45 $v / v)$. The buffer used in mobile phase contains $0.1 \mathrm{M}$ sodium perchlorate monohydrate in double distilled water $\mathrm{pH}$ adjusted 3.0 with trifluoroacetic acid. The instrumental settings are flow rate of $1.5 \mathrm{ml} \mathrm{min}^{-1}$, column temperature at $30^{\circ} \mathrm{C}$, and detector wavelength of $215 \mathrm{~nm}$ using a photodiode array detector. The resolution between hydrochlorothiazide and telmisartan founds to be more than 5. Theoretical plates for hydrochlorothiazide and telmisartan were 13022 and 6629 respectively. Tailing factor for hydrochlorothiazide and telmisartan was 0.94 and 0.98 respectively. Telmisartan, hydrochlorothiazide and their combination drug products stressed samples were analysed by the proposed method. The described method shows excellent linearity over a range of 70 to $130 \%$ of target analyte concentration. The correlation coefficient for telmisartan and hydrochlorothiazide are 0.9999 . The relative standard deviation for six measurements in two sets of each drug in tablets is always less than $2 \%$. The proposed method was found to be suitable and accurate for quantitative determination and stability study of telmisartan and hydrochlorothiazide in pharmaceutical preparations.
\end{abstract}

Keywords: Hydrochlorothiazide, Liquid chromatography, Method validation, Pharmaceutical preparation, Telmisartan.

\section{INTRODUCTION}

Telmisartan, a nonpeptide molecule, is chemically 4'-[(1,4-dimethyl2'-propyl [2,6'-1H-benzimidazol]-1'-yl) methyl]-[1,1'-biphenyl]-2carboxylic acid and Hydrochlorothiazide is chemically [2S,3aS,6aS]-1[(2S)-2-[[(1S)-1-(Ethoxycarbonyl)-3-phenylpropyl]amino]-1-oxopropyl] octahydrocyclopenta[b]pyrrole-2-carboxylic $\operatorname{acid}^{1}$. Telmisartan is an angiotensin II receptor antagonist that is highly selective for type 1 angiotensin II receptor. Angiotensin II is the principle pressor agent of the rennin-angiotensin system, with effects that include vasoconstriction, stimulation of synthesis and release of aldosterone, cardiac stimulation, and renal reabsorbtion of sodium. Hydrochlorothiazide is a highly lipophilic, long acting ACE inhibitor. The drug is used for treating blood pressure and congestive heart failure. It effectively reduces both supine and standing blood pressure without significant alteration in the pulse rate. A combination of $40 \mathrm{mg}$ of telmisartan and $5 \mathrm{mg}$ of hydrochlorothiazide is available commercially as tablets. Telmisartan and hydrochlorothiazide combination is used to lower blood pressure ${ }^{2}$.

Stability testing forms an important part of the process of drug product development. The purpose of stability testing is to provide evidence on how quality of a drug substance or drug product varies with time under the influence of a variety of environmental factors such as temperature, humidity, light and enables recommendation of storage conditions, retest periods and shelf life to be established. The two main aspects of drug product that play an important role in shelf life determinations are assay of active drug and degradants generated during stability study. The objective of this work was to develop an analytical LC procedure, which would serve as stability indicating assay method for combination drug product of telmisartan and hydrochlorothiazide.

The literature survey reveals that several methods were reported for the individual estimation of telmisartan and hydrochlorothiazide. The methods ${ }^{3-11}$ for telmisartan in combination with other drugs in plasma, serum and in tablets by high-performance liquid chromatography (HPLC) and $^{12-17}$ for the estimation of hydrochlorothiazide in combination with other drugs in serum and is in tablets by high-performance liquid chromatography (HPLC). A stability indicating LC method has been reported for telmisartan as well as hydrochlorothiazide. None of the reported analytical procedures describe a method for simultaneous determination of the telmisartan and hydrochlorothiazide in combined pharmaceutical dosage form in presence of their degradation products.

If the reported individual methods are applied for the analysis of the tablets containing telmisartan and hydrochlorothiazide, it would require double time for analysis, as compared with the method would not be rapid, less expensive, or economical, whereas the simultaneous determination of the ingredients of the tablets would save analysis time and also economy.

In the present study attempts were made to develop a rapid, economical, precise and accurate method for the simultaneous estimation of the ingredients of this combination in presence of their degradants.

\section{EXPERIMENTAL}

Chemicals and Reagents

Telmisartan and hydrochlorothiazide standards were obtained from Lupin pharmaceutical Ltd. (Mumbai, India), trifluoroacetic acid and acetonitrile (HPLC grade) were obtained from Merck Fine Chemicals (Mumbai, India). Sodium perchlorate monohydrate obtained from Lancaster. Sodium hydroxide $(\mathrm{NaOH})$, hydrochloric acid $(\mathrm{HCl})$ and hydrogen peroxide $\left(\mathrm{H}_{2} \mathrm{O}_{2}\right)$ were from Qualigens fine chemicals (Glaxo Ltd.) The 0.45 -Pump nylon filter was obtained from Advanced Micro devices Pvt. Ltd., (Ambala Cantt, India). The combination product (Telipril 5) of telmisartan and hydrochlorothiazide label claims (telmisartan $40 \mathrm{mg}$ and hydrochlorothiazide $5 \mathrm{mg}$, Sun pharmaceutical, Mumbai, India) were purchased from the market. Double distilled water was used throughout the experiment.

Chromatographic Conditions

A chromatographic system used was Agilent - 1100 series comprised of degasser, quaternary pump, auto injector, column compartment, photodiode array detector and the system was controlled through Chemstation software. ACE $5 \mathrm{C}_{18}(250 \times 4.6 \mathrm{~mm}, 5 \mathrm{um}$, Advance chromatography Ltd., US) i.d. column, maintained at $30^{\circ} \mathrm{C}$ using column oven, eluted with mobile phase at the flow rate of $1.5 \mathrm{ml} \mathrm{min}^{-1}$. The mobile phase consisted of buffer-acetonitrile $(55: 45 \mathrm{v} / \mathrm{v})$. The buffer used in mobile phase contains $0.1 \mathrm{M}$ sodium perchlorate monohydrate in double distilled water $\mathrm{pH}$ adjusted 3.0 with trifluoroacetic acid filtered through $0.45 \mu \mathrm{m}$ nylon filter and degassed in ultrasonic bath prior to use. Measurements were made with injection volume $10 \mu \mathrm{l}$ and ultraviolet (UV) detection at $215 \mathrm{~nm}$. For analysis of forced degradation samples, the photodiode array detector was used in scan mode with a scan range of 200 $-400 \mathrm{~nm}$. The peak homogeneity was expressed in terms of peak purity and was obtained directly from the spectral analysis report obtained using abovementioned software.

\section{Standard Stock Solutions}

Standard solutions were prepared by dissolving the drugs in the diluents and diluting them to the desired concentration. Diluents used for the standards and sample preparation was prepared as follow: diluent A was composed of methanol and Acetonitrile in the ratio of 50:50 $(v / v)$ and diluents B was composed of water and acetonitrile in the ratios of 45:55 $(\mathrm{v} / \mathrm{v})$.

\section{Telmisartan}

A $50 \mathrm{mg}$ sample of telmisartan (99.97\%) was accurately weighed, transferred in a $50 \mathrm{ml}$ volumetric flask, and dissolved with the diluent $\mathrm{A}$.

\section{Hydrochlorothiazide}

A $25 \mathrm{mg}$ sample of hydrochlorothiazide (99.98\%) was accurately weighed, transferred in a $50 \mathrm{ml}$ volumetric flask, and dissolved with diluent A.

\section{Mixed standard Solution}

A mixed standard solution was prepared from these stock solutions by transferring $10 \mathrm{ml}$ of telmisartan standard solutions, $2.5 \mathrm{ml}$ of 
hydrochlorothiazide standard solution in a $50 \mathrm{ml}$ volumetric flask and diluted with diluent B. This solution contained $200 \mu \mathrm{g} \mathrm{ml}^{-1}$ of telmisartan and $25 \mu \mathrm{g}$ $\mathrm{ml}^{-1}$ of hydrochlorothiazide.

\section{Preparation of sample}

Ten tablets were weighed and finely powdered. A quantity of powder equivalent to one tablet containing $40 \mathrm{mg}$ of telmisartan and $5 \mathrm{mg}$ of hydrochlorothiazide was transferred in a $100 \mathrm{ml}$ volumetric flask. To this flask, $50 \mathrm{ml}$ of diluent A was added, and the solution was sonicated for $25 \mathrm{~min}$. with intermittent shaking. The solution was cooled to ambient temperature. Then make up the volume with diluent B and centrifuged at 10,000 rpm for 10 min. The centrifuged solution filtered through $0.45-\mu$ filter. From the filtered solution, $5 \mathrm{ml}$ of solution was transferred into a $10 \mathrm{ml}$ volumetric flask and diluted to volume with diluent B.

\section{Procedure for forced degradation study of drug substances}

Forced degradation of each drug substances and the drug product was carried out under thermolytic, photolytic, acid/base hydrolytic and oxidative stress conditions. The ICH guideline ${ }^{18}$ state the minimum desired exposure as $200 \mathrm{Wh} / \mathrm{m}^{2}$, which corresponds to a change in absorbance of $0.5 \mathrm{AU}$ of quinine actinometer at $400 \mathrm{~nm}$. This change was observed in $24 \mathrm{hrs}$. of irradiation. A second photolytic stress test experiment with greater irradiation time $48 \mathrm{hrs}$.

Acidic degradation: Weigh accurately about $20 \mathrm{mg}$ of telmisartan and dissolve in $10 \mathrm{ml}$ of diluent $\mathrm{A}$, then add $10 \mathrm{ml} 1 \mathrm{~N} \mathrm{HCl}$ keep the mixture at $60^{\circ} \mathrm{C}$ for two hours (hrs.) in water bath. Allow the solution to attend ambient temperature, then neutralized the solution with $1 \mathrm{~N} \mathrm{NaOH}$ to $\mathrm{pH} 7$ and make up the volume to $50 \mathrm{ml}$ with diluent $\mathrm{B}$.

Weigh accurately about $10 \mathrm{mg}$ of hydrochlorothiazide and dissolve in $5 \mathrm{ml}$ of diluent $\mathrm{A}$, then add $10 \mathrm{ml} 1 \mathrm{~N} \mathrm{HCl}$ keep the mixture at $60^{\circ} \mathrm{C}$ for two hrs. in water bath. Allow the solution to attend ambient temperature, then neutralized the solution with $1 \mathrm{~N} \mathrm{NaOH}$ to $\mathrm{pH} 7$ and make up the volume to $200 \mathrm{ml}$ with diluent $\mathrm{B}$.

Alkali degradation: Weigh accurately about $20 \mathrm{mg}$ of telmisartan and dissolve in $10 \mathrm{ml}$ of diluent $\mathrm{A}$, then add $10 \mathrm{ml} 0.1 \mathrm{~N} \mathrm{NaOH}$ keep the mixture at $60^{\circ} \mathrm{C}$ for two hrs. in water bath. Allow the solution to attend ambient temperature, then neutralized the solution with $1 \mathrm{~N} \mathrm{HCl}$ to $\mathrm{pH} 7$ and the volume made up to $50 \mathrm{ml}$ with diluent $\mathrm{B}$.

Weigh accurately about $10 \mathrm{mg}$ of hydrochlorothiazide and dissolve in $5 \mathrm{ml}$ of diluent $\mathrm{A}$, then add $10 \mathrm{ml} 0.1 \mathrm{~N} \mathrm{NaOH}$ keep the mixture at ambient temperature for twenty minutes. Then neutralized the solution with $1 \mathrm{~N} \mathrm{HCl}$ to $\mathrm{pH} 7$ and the volume made up to $200 \mathrm{ml}$ with diluent B.

Oxidative degradation: Weigh accurately about $20 \mathrm{mg}$ of telmisartan and dissolve in $10 \mathrm{ml}$ of diluent $\mathrm{A}$, then add $10 \mathrm{ml} 30 \% \mathrm{H}_{2} \mathrm{O}_{2}$ keep the mixture at $60^{\circ} \mathrm{C}$ for two hrs. in water bath. Allow the solution to attend ambient temperature and the volume made up to $50 \mathrm{ml}$ with diluent $\mathrm{B}$.

Weigh accurately about $10 \mathrm{mg}$ of hydrochlorothiazide and dissolve in $5 \mathrm{ml}$ of diluent $\mathrm{A}$, then add $10 \mathrm{ml} 30 \% \mathrm{H}_{2} \mathrm{O}_{2}$ keep the mixture at $60^{\circ} \mathrm{C}$ for two hrs. in water bath. Allow the solution to attend ambient temperature and the volume made up to $200 \mathrm{ml}$ with diluent $\mathrm{B}$.

Thermal degradation: About $50 \mathrm{mg}$ of drug substances were kept at $80^{\circ} \mathrm{C}$ for $28 \mathrm{hrs}$. Then the solution was prepared to achieve $400 \mathrm{\mu g} \mathrm{ml}^{-1}$ of telmisartan and $50 \mu \mathrm{g} \mathrm{ml}^{-1}$ of hydrochlorothiazide.

UV-Short (254 $\mathbf{~ m m}$ ) degradation: About $50 \mathrm{mg}$ of drug substances were exposed to UV short light for $24 \mathrm{hrs}$. Then the solution was prepared to achieve $400 \mu \mathrm{g} \mathrm{ml}^{-1}$ of telmisartan and $50 \mu \mathrm{g} \mathrm{ml}^{-1}$ of hydrochlorothiazide.

UV-Long (366 nm) degradation: About $50 \mathrm{mg}$ of drug substances were exposed to UV long light for $48 \mathrm{hrs}$. Then the solution was prepared to achieve $400 \mu \mathrm{g} \mathrm{ml} l^{-1}$ of telmisartan and $50 \mu \mathrm{g} \mathrm{ml}^{-1}$ of hydrochlorothiazide.

The 20 watt short wave $(254 \mathrm{~nm})$ and long wave $(366 \mathrm{~nm})$ UV lamp were used for the photo degradation study. The samples were placed at $15 \mathrm{~cm}$ from lamp. The temperature was ambient. The ICH guideline Photostability testing of new drug substances and products Q1(B) has given the specification of Ligh source. In option one ID65 is the equivalent indoor indirect daylight standard. For a light source emitting significant radiation below $320 \mathrm{~nm}$. In option two a near UV fluorescent lamp having a spectral distribution from $320 \mathrm{~nm}$ to 400 nm.

\section{Procedure for forced degradation study of drug products}

A forced degradation study of drug products in Acidic, Basic and Oxidative condition was carried out using centrifuged and filtered solution (as described in preparation of sample).

For thermolytic and photolytic degradation, A quantity of powder equivalent to one tablet containing $40 \mathrm{mg}$ of telmisartan and $5 \mathrm{mg}$ of hydrochlorothiazide was exposed. Then the solutions were prepared as described in preparation of sample.

\section{RESULTS AND DISCUSSION}

\section{Optimization of the chromatographic conditions}

To develop stability indicating method different stationary phases like $\mathrm{C} 18$, $\mathrm{CN}$, different mobile phases containing buffers like phosphate, ammonium acetate and trifluoroacetic acid with different $\mathrm{pH}(3-5)$ and organic modifier (acetonitrile) were used.

Our objective of chromatographic method development was to achieve peak tailing factor $<2$, retention time in between 3 to 10 minutes, Along with resolution between telmisartan and hydrochlorothiazide $>2$.

The chromatographic separation was achieved using ACE 5 C18 $(250 \mathrm{x}$ $4.6 \mathrm{~mm}$ i.d.) column. Changing the composition of mobile phase optimized the chromatographic method. Resolution between hydrochlorothiazide and telmisartan was observed on any $\mathrm{C} 18$ or $\mathrm{CN}$ column but it was difficult to separate both drugs degradants on these columns. ACE 5 column shows better performance as compared to other columns.

From the development studies, it was determined that $0.1 \mathrm{M}$ sodium perchlorate monohydrate in water $\mathrm{pH}$ adjusted to 3 with trifluoroacetic acid and acetonitrile in the ration of $55: 45(v / v)$, the flow rate of mobile phase was $1.5 \mathrm{ml} \mathrm{min}{ }^{-1}$ and column temperature at $30^{\circ} \mathrm{C}$. The analytes of this combination had adequate retentions, peak shape, less tailing, more resolution and the chromatographic analysis time was less than $12 \mathrm{~min}$. In optimized conditions telmisartan, hydrochlorothiazide and their degradants were well separated. Typical retention times of hydrochlorothiazide and telmisartan were about 3.17 and $11.26 \mathrm{~min}$ respectively. Resolution between hydrochlorothiazide and telmisartan founds to be more than 5 .

Singh and Bakshi, in their article on stress testing ${ }^{19}$ suggested a target degradation of $20-80 \%$ for the establishing stability indicating nature of the assay method, as even intermediate degradation products should not interfere with any stage of drug analysis. Though conditions used for forced degradation were attenuated to achieve degradation in the range of $20-80 \%$, this could not be achieved in case of acidic, thermal and photolytic degradation even after exposure for prolonged duration. During the initial forced degradation experiments, it was observed that basic hydrolysis was a fast reaction for hydrochlorothiazide and almost complete degradation occurred when $0.5 \mathrm{~N}$ $\mathrm{NaOH}$ solution is used. Both the drugs showed extensive degradation in alkali hydrolytic and oxidative condition. Table 1 indicates the extent of degradation of hydrochlorothiazide and telmisartan under various stress conditions. Chromatographic peak purity data was obtained from the spectral analysis report and a peak purity value greater than 990 indicates a homogeneous peak. The peak purity values for analyte peaks, hydrochlorothiazide and telmisartan, were in the range of 999-1000 for drug substance and in the range of 997-1000 for tablets, indicating homogeneous peaks and thus establishing the specificity of assay method. Fig. 1. Show the chromatograms of hydrochlorothiazide and telmisartan tablet solution. Figs. 2(a-i) show the chromatograms of blanks, drug substance and drug products forced degradation.

Table 1. Results of analysis of forced degradation study samples using proposed method, indicating percentage degradation and peak purity of hydrochlorothiazide and telmisartan in chromatograms.

\begin{tabular}{|c|c|c|c|c|}
\hline $\begin{array}{c}\text { Stress } \\
\text { condition }\end{array}$ & $\begin{array}{c}\text { Hydrochloro- } \\
\text { thiazide } \\
\text { (\%) degradation }\end{array}$ & $\begin{array}{c}\text { Peak } \\
\text { purity }\end{array}$ & $\begin{array}{c}\text { Telmisartan } \\
(\%) \\
\text { degradation }\end{array}$ & $\begin{array}{c}\text { Peak } \\
\text { purity }^{\mathrm{a}}\end{array}$ \\
\hline Acidic & 0.5 & 999.924 & 0.21 & 999.844 \\
Alkali & 44.03 & 999.508 & 12 & 999.677 \\
Oxidative & 35.61 & 997.517 & 24.26 & 999.972 \\
Thermal & No degradation & 999.816 & 0.05 & 999.827 \\
UV-short & No degradation & 999.697 & 0.06 & 999.908 \\
UV-long & No degradation & 999.857 & 0.05 & 999.864 \\
\hline
\end{tabular}

${ }^{a}$ peak purity values in the range of 990-1000 indicate a homogeneous peak.

\section{METHOD VALIDATION}

\section{Specificity}

Photodiode array detection was used as an evidence of the specificity of the method and to evaluate the homogeneity of the drug peak. The peak purity values are more than 997 for drug substances as well as drug products at 215 $\mathrm{nm}$, which shows that the peaks of analyte were pure and also that formulation excipients and degradants were not interfering with the analyte peaks.

Calibration and linearity:

Linearity of the method was tested from 70 to $130 \%$ of the targeted level 
of the assay concentration (telmisartan, $200 \mu \mathrm{g} / \mathrm{mL}$ and hydrochlorothiazide 25 $\mu \mathrm{g} / \mathrm{mL}$ ) for both analytes. Mixed standard solutions containing $140-260 \mu \mathrm{g} /$ $\mathrm{mL}$ of telmisartan and $17.5-32.5 \mu \mathrm{g} / \mathrm{mL}$ of hydrochlorothiazide were used for Linearity.

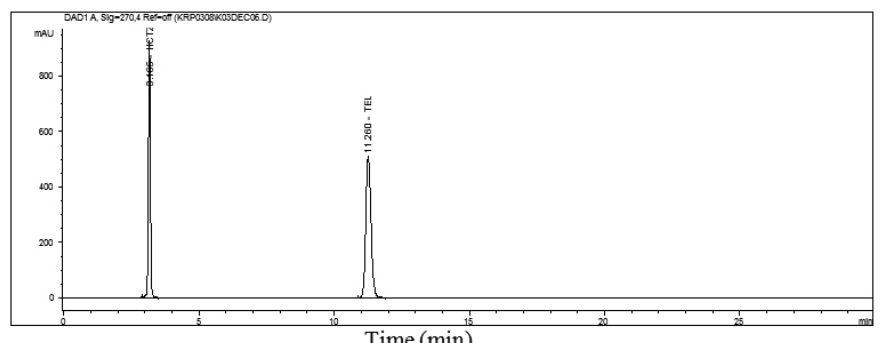

Fig.1. A chromatogram of the tablet: Hydrochlorothiazide (3.17 min.) and Telmisartan (11.26 min.)

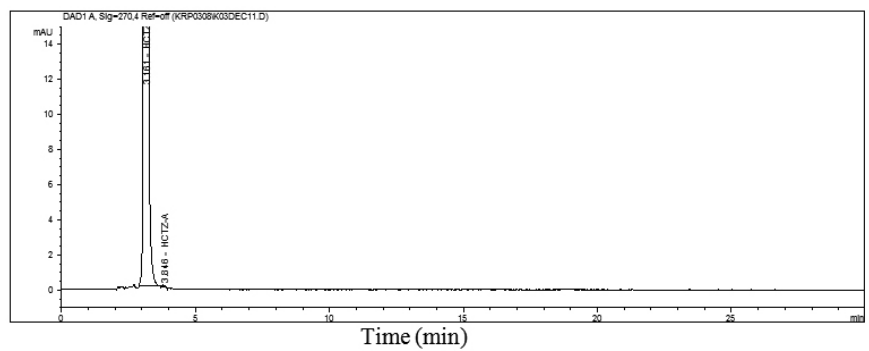

Fig. 2. (a), (b) and (c): Chromatograms of acid hydrolysis degraded hydrochlorothiazide, telmisartan and tablet solution respectively.

Fig. 2. (a)

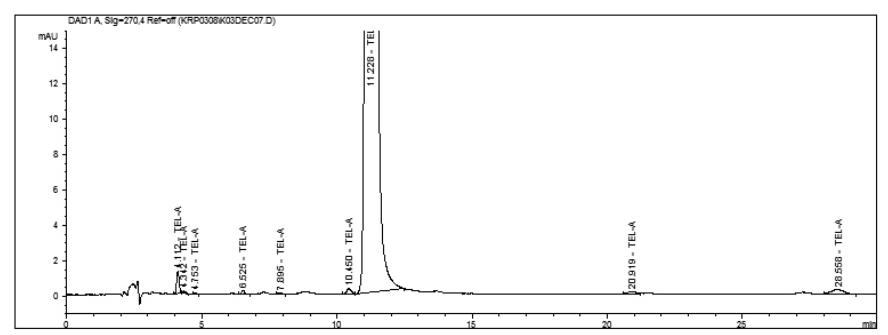

Fig. 2. (b)

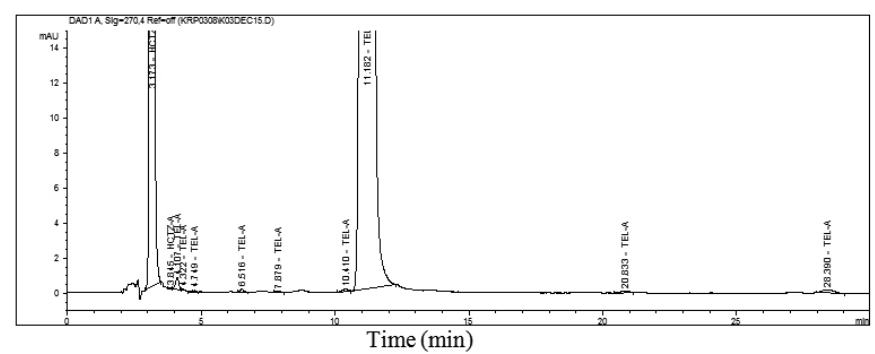

Fig. 2. (c)

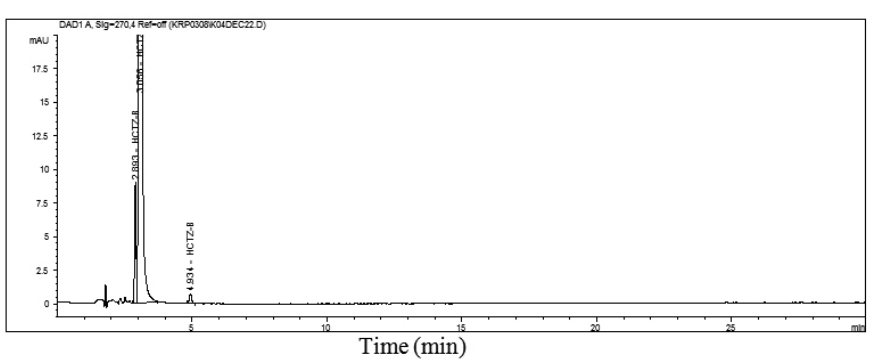

Fig. 2. (d), (e) and (f): Chromatograms of alkali hydrolysis degraded hydrochlorothiazide, telmisartan and tablet solution respectively.

Fig. 2. (d)

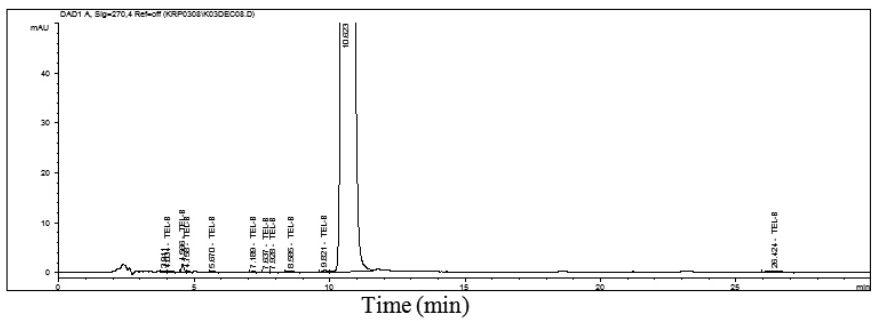

Fig. 2. (e)

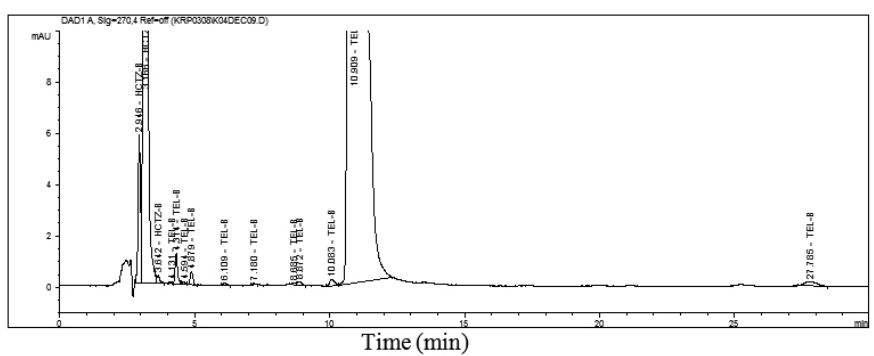

Fig. 2. (f)

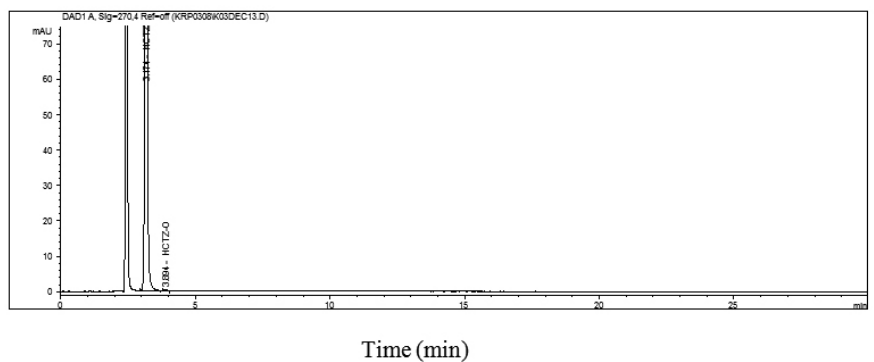

Fig. 2. (g), (h) and (i): Chromatograms of oxidative degraded hydrochlorothiazide, telmisartan and tablet solution respectively.

Fig. 2. (g)

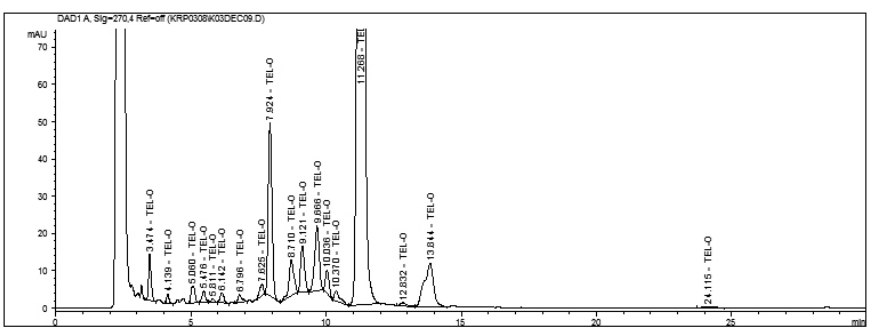

Time (min)

Fig. 2. (h) 


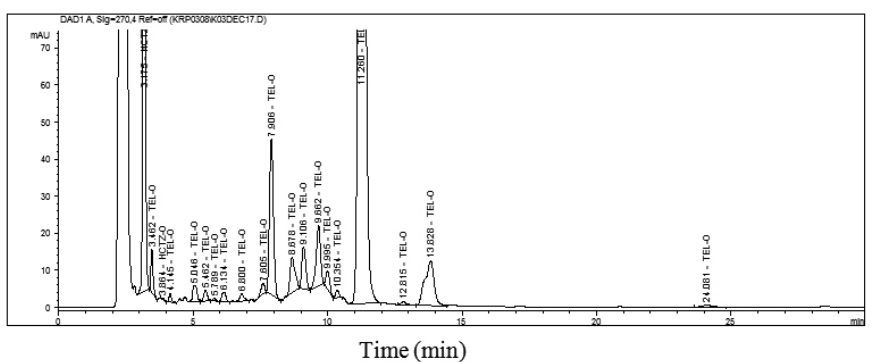

Fig. 2. (i)

Linearity solutions were injected in triplicate. The calibration graphs were obtained by plotting peak area ratio against the concentration of the drugs. The equations of the calibration curves for hydrochlorothiazide and telmisartan obtained were $y=12.663 x-1.042$ and $y=40.77 x+0.9227$ respectively. In the simultaneous determination, the calibration graphs were found to be linear in the aforementioned concentrations with correlation coefficients 0.9999 and $\%$ RSD for slope of hydrochlorothiazide and telmisartan were 0.21 and 0.16 respectively.

Precision (repeatability):

The precision of the method was studied by determining the concentrations of each drug in the tablets six times. The area \%RSD for hydrochlorothiazide and telmisartan were 0.16 and 0.08 respectively. The results of the precision study indicate that the method is reliable $(\mathrm{RSD} \%<2$ ).

Accuracy (recovery test)

Accuracy of the method was studied by recovery experiments. The recovery experiments were performed by adding known amounts of the drugs in the placebo. The recovery was performed at three levels $80 \%$, $100 \%$ and $120 \%$ of the label claim of the tablet (40mg of telmisartan and 5 $\mathrm{mg}$ of hydrochlorothiazide). Placebo equivalent to one tablet was transferred into a $100 \mathrm{ml}$ volumetric flask, and the amounts of telmisartan and of hydrochlorothiazide at $80 \%, 100 \%$ and $120 \%$ of the label claim of the tablet were added to it. The recovery samples were prepared as per the procedure mentioned, and then $5 \mathrm{ml}$ of each of the solutions were transferred into a 10 $\mathrm{ml}$ volumetric flask and diluted to volume with diluent B. Three samples were prepared for each recovery level. The solutions were then analyzed, and the percentage recoveries were calculated from the calibration curve. The recovery values for hydrochlorothiazide and telmisartan ranged from $99.97 \%$ to $100.35 \%$ and $99.78-100.54 \%$ respectively. The average recovery of three levels (nine determinations) for hydrochlorothiazide and telmisartan were $100.15 \%(0.19)$ and $100.09 \%(0.40)$ respectively. RSD shown in parenthesis.

\section{Intermediate precision (reproducibility)}

Intermediate precision of the method was determined by analyzing the samples six times on different days, by different Chemists, by using different analytical columns of the same make and different HPLC systems. The percentage assay was calculated using calibration curves. The assay results of chemist 1 for hydrochlorothiazide and telmisartan were 99.20 and 99.70 respectively. The assay results of chemist 2 for hydrochlorothiazide and telmisartan were 98.4 and 99.95 respectively.

\section{Robustnes}

The robustness of a method is the ability of method to remain unaffected by small changes in parameters. To determine robustness of the method, experimental conditions were purposely altered and chromatographic resolution between telmisartan and hydrochlorothiazide were evaluated.

The flow rate of the mobile phase was $1.5 \mathrm{ml} \mathrm{min}^{-1}$. To study the effect of flow rate on resolution of telmisartan and hydrochlorothiazide, it was changed to 0.15 units from 1.5 to $1.65 \mathrm{ml} \mathrm{min}^{-1}$ and $1.35 \mathrm{ml} \mathrm{min}^{-1}$. The effect of column temperature on resolution was studied at $28^{\circ} \mathrm{C}$ and $32{ }^{\circ} \mathrm{C}$ instead of $30^{\circ} \mathrm{C}$, while other mobile phase components were held constant. The effect of mobile phase composition on resolution of hydrochlorothiazide and telmisartan was studied at buffer: acetonitrile $(53: 47 \mathrm{v} / \mathrm{v})$ and $(57: 43 \mathrm{v} / \mathrm{v})$.

At all conditions resolution between hydrochlorothiazide and telmisartan was found to be more than 5 .

Determination of limit of quantification and limit of detection (LOQ \& LOD)

The LOD and LOQ for hydrochlorothiazide and telmisartan were determined at a signal-to-noise ratio of 3:1 and 10:1 respectively by injecting a series of dilute solutions with known concentration ${ }^{20}$. The LODs for hydrochlorothiazide and telmisartan were 0.06 and $0.03 \mu \mathrm{g} \mathrm{ml}^{-1}$, and the LOQs were 0.20 and $0.10 \mu \mathrm{g} \mathrm{ml}^{-1}$ respectively for $10 \mu \mathrm{l}$ injection volume.

\section{Solution stability}

The stability of the standard solution was tested at intervals of 30 and 48 hours. The stability of solutions was determined by comparing results of area\%, resolution and peak purity of hydrochlorothiazide and telmisartan. The area $\%$ values were within $0.5 \%$ after $48 \mathrm{hrs}$. The results indicate that the solutions were stable for $48 \mathrm{hrs}$. at ambient temperature as there was no formation of any unknown peak and solution remains stable. The RSD of peak area\% ratio, peak purity, asymmetry factor, capacity factor and resolution of the peaks were calculated. The results are shown in Table 2.

Table 2. Results of solution stability after 48 hours.

\begin{tabular}{|c|c|c|}
\hline Parameter & Hydrochlorothiazide & Telmisartan \\
\hline Resolution & & 5.76 \\
\% RSD (peak area) & 0.42 & 0.23 \\
Peak purity & 999.784 & 999.984 \\
Asymmetry factor & 0.98 & 1.02 \\
Capacity factor & 3.20 & 4.37 \\
\hline
\end{tabular}

\section{Determination of active ingredients in tablets}

The contents of two drugs in tablets were determined by the proposed method using the calibration curve. The determinations were done in two sets, one for precision and the second for ruggedness. Six samples were prepared for each set. The assay results for hydrochlorothiazide and telmisartan were $99.20 \%$ and $99.70 \%$ respectively. The chromatogram of the tablet sample is shown in Fig. 1.

\section{CONCLUSION}

The isocratic RP-LC method developed for analysis of binary mixture of hydrochlorothiazide and telmisartan in their pharmaceutical preparations is precise, accurate and with short run time. The method was fully validated showing satisfactory data for all the method validation parameters tested. The developed method is a stability indicating separates degradants and can be conveniently used by quality control department to determine the assay of pharmaceutical preparations and also stability samples.

\section{ACKNOWLEDGMENT}

The authors are grateful to the Lupin pharmaceutical (Mumbai, India) for gift samples (telmisartan and hydrochlorothiazide) and Head-Department of chemical technology, Dr. Babasaheb Ambedkar Marathwada University, Aurangabad, India for providing laboratory facility for this research work.

\section{REFERENCES}

1. Merck Index, 13 th edn. Merck \& Co., inc., USA (2001)

2. S. D. Jain, S. Biradkar, I. Periyandavar, S. S. Sodhi, K. Anwariddin, A. Gawde, V. Baliga, K. Gandewar, A. Desai, Curr. Ther. Res., 66(nº6), 630 (2005)

3. M. Sharpe, B. Jarvis, L. Karen, Drugs, 61(10), 1501(2001)

4. J. Shen, Pharmazie, 60(6), 418 (2005)

5. N. Jing, Z. Qun, H. Jingfang, X. Bingren, T.Q. Feng, J. Sep. Sci., 29(5), $650(2006)$

6. P. Li, Y. Wang, Y. Tang, J.P. Fawcett, Y. Cui, J. Chromatogr. B. Analyt. Tecnol. Biomed. Life. Sci., 828(1-2), 126 (2005)

7. N. Jing, M. Zhang, Y. Fan, Y. Wen, B. Xing, Y.Q. Feng, Chromatogr. B. 828, 62 (2005)

8. M.S. Pallwd, M.N. Ragesh, P. M. Chatter, A.R. Bhat, Ind. J. Pharma. Sci., 67, $108(2005)$

9. M.S. Pallwd, M.N. Ragesh, P. M. Chatter, A.R. Bhat, Ind. J. Pharma. Sci., 68, 685 (2006)

10. M. V. Kumar, P.R. Muley, Indian Pharm., 36, 69 (2005)

11. S. B. Wankhede, M. K. Tajne, K. R. Gupta, S. G. Wadodkar, Ind. J. Pharma. Sci., 69, 298 (2007)

12. F. Belal, I.A. Al-Zaagi, E.A. Gadkariem, M.A. Abounassif, J. Pharma Biomed. Anal., 24(3), 335 (2001)

13. Lu Xiao-yang, Jian-zhong, Shen-Tu, Liu Jian. J. Pharma. Biomed. Anal., 40(2), 478 (2006)

14. L. Hanysova, M. Vaclavkova, J. Dohnal, J. Klimes, J. Pharma. Biomed. Anal., 37(5), 1179 (2005) 
15. L. Manna, L. Volvo, S. Alimonti, J. Chromatographia., 53(1), S271 (2006)

16. M. M. Baing, V. V. Vaidya, R. T. Sane, S. N. Menon, K. Dalvi J. Chromatographia, 64(5-6), 293 (2006)

17. R. Gandhimathi, T. K. Ninan, A. Varghese, INDIAN DRUGS-BOMBAY. 41(1), 36 (2004)
18. International Conference on Harmonisation: Guidelines for the "photostability testing of new drug substances and products, step 4", Q1B (1996).

19. S. Singh, M. Bakshi, Pharm. Technol., 26, 24 (2000)

20. Validation of analytical procedures: Text and Methodology. In ICH Harmonized Tripartite Guidelines Q2 (R1), November (2005). 